ISSN 2075-4701

www.mdpi.com/journal/metals

Article

\title{
Structure and Mössbauer Analysis of Melt-Spun Fe-Pd Ribbons Containing $\mathrm{Ni}$ and $\mathrm{Co}$
}

\author{
Hanen Rekik ${ }^{1}$, Mahmoud Chemingui ${ }^{1}$, Tarek Bachaga ${ }^{1,2, *}$, Amal Cherif ${ }^{1}$, Pere Bruna ${ }^{3}$, \\ Joan Joseph Sunol ${ }^{2}$ and Mohamed Khitouni ${ }^{1}$
}

1 Laboratory of Inorganic Chemistry, UR 11ES73, University of Sfax, B.P.1171, Sfax 3000, Tunisia; E-Mails: rekik.hanen@yahoo.fr (H.R.); chmingui_mahmoud@yahoo.fr (M.C.); amal.cherif@hotmail.fr (A.C.); khitouni@yahoo.fr (M.K.)

2 Department of Physics, University of Girona, Campus Montilivi s/n, Girona 17071, Spain; E-Mail: joanjosep.sunyol@udg.edu

3 Department of Applied Physics, University of Catalonia, Barcelona. Tech, Esteve Terradas 5, Castelldefels 08860,Spain; E-Mail: pere.bruna@upc.edu

* Author to whom correspondence should be addressed; E-Mail: bachagatarak@yahoo.fr; Tel.: +216-595-060-715 (ext. 00216); Fax: +216-742-744-37.

Academic Editor: Kurt R. Ziebeck

Received: 15 April 2015 / Accepted: 25 May 2015 / Published: 5 June 2015

\begin{abstract}
Fe} 68.45 \mathrm{Pd} 28.21 \mathrm{Co} 1.66 \mathrm{Ni} 1.66$ alloy in ribbon geometry was produced by melt spinning. The microstructure of the samples was examined using scanning electron microscopy. The structural identification of the as-spun ribbon sample and the annealed ones was performed by means of X-ray diffraction. All the Bragg peaks were indexed based on an fcc type structure of $(\gamma-\mathrm{Fe}, \mathrm{Pd})$ phase with a lattice parameter $a=3.742$ (3) $\AA$. This result was proved by Mössbauer technique. The annealed ribbon at $600{ }^{\circ} \mathrm{C}$ shows an L10 ordered fct structure. An endothermic reaction at $T=358^{\circ} \mathrm{C}$ followed by an exothermic one at $390{ }^{\circ} \mathrm{C}$ were observed on heating. These reactions were attributed to the Curie temperature of nickel and to the annihilation of an excess of quenched-in vacancies, respectively.
\end{abstract}

Keywords: shape memory alloys; structural; microstructure; Mössbauer 


\section{Introduction}

Fe-Pd-based alloys have attracted much interest since the beginning of the 1980, initially due to their invar properties [1], giant magnetostrictive strain [2], and magnetic anisotropy with the potential of perpendicular magnetic recording [3]. Most recently, they have been the subject of many research studies as a promising ferromagnetic shape memory (FSM) material [4]. In addition, these alloys show higher Curie temperature $T_{\mathrm{c}}$ and have excellent mechanical properties [5]. The structural and magnetic properties of $\mathrm{Fe}-\mathrm{Pd}$ alloys have been widely studied, and the most initial characterization work was given by the group of Oshima [6-9]. It has been reported that the alloys with the compositional range 29-32 at. \% Pd undergo a thermoelastic martensitic transformation (MT) from a face-centered cubic (fcc) austenitic phase to a face-centered tetragonal (fct) low temperature martensitic phase. The fct martensite transforms into a body-centered tetragonal (bct) structure after further cooling [7]. This transformation is non-thermoelastic, such that the formed bct martensite persists on the alloy. Besides, it has been shown that the fcc-fct and fct-bct transformations temperatures strongly depend on composition [3].

On the other hand, the addition of other elements can affect the martensitic transformation temperatures of FePd alloys. This hypothesis has been confirmed in the Ni-Mn-Ga-Co [10] and Fe-Pd-Mn systems [11]. However, the addition of a new alloying element may favor the stabilization of the fct martensite as suggested for $\mathrm{Fe}_{70} \mathrm{Pd}_{30}$ and $\mathrm{Fe}-\mathrm{Pd}-\mathrm{Pt}$ alloys [12]. In fact, to the best of our knowledge, there is a few works that have addressed this problem [13,14]. It is quite important to answer the question pertaining to the influence of ternary and quaternary additions on this phase transition, especially for the $\mathrm{Ni}$ and Co elements. The present work presents the experimental evidence for the understanding of this addition effects.

\section{Experimental Section}

Ingots of about $2 \mathrm{~g}$ with nominal composition $\mathrm{Fe}_{68.45} \mathrm{Pd}_{28.21} \mathrm{Co}_{1.66} \mathrm{Ni}_{1.66}$ were prepared by arc-melting in argon atmosphere. As-spun ribbons about $1.5-2.0 \mathrm{~mm}$ in width, several $\mathrm{cm}$ in length and around $10 \mu \mathrm{m}$ in thickness were produced by single roller melt spinning at $4380 \mathrm{rpm}$ in argon atmosphere. The as-received ribbons were encapsulated in vacuum quartz capsules in order to prevent oxidation of the ribbons at high temperatures. These ribbons were then annealed at $600{ }^{\circ} \mathrm{C}$ for $1 \mathrm{~h}$. The microstructure of the samples was examined by using scanning electron microscopy (DSM960A; Zeiss, Norman, OK, USA; SEM) equipped with energy-dispersive X-ray spectrometry. X-ray diffraction (Bruker D8 Advance diffractometer in a 20-geometry; Manning Park Billerica, MA, USA; XRD) analyses were performed using $\mathrm{Cu}-\mathrm{K}_{\alpha}$ radiation. The transmission Mössbauer spectrum was obtained at room temperature and room pressure using a conventional constant acceleration spectrometer (Wissenschaftliche Elektronik $\mathrm{GmbH}$, Starnberg, Germany) with a $25 \mathrm{mCi}$ source of ${ }^{57} \mathrm{Co}$ in $\mathrm{Rh}$ matrix. The experimental spectrum was fitted with Brand's NORMOS program [15], using a histogram magnetic hyperfine field distribution with linear correlation between the isomer shift, $\delta$, and the magnetic field, $B_{\text {hf. The isomer shift values }}$ are given relative to room temperature $\alpha$-Fe. The thermal analyses were performed by means of differential scanning calorimetry (DSC822 apparatus of Mettler Toledo; Columbus, OH, USA; DSC) instrument with a heating/cooling rate of $10 \mathrm{~K} / \mathrm{min}$ up to $600{ }^{\circ} \mathrm{C}$ under constant argon flow. 


\section{Results and Discussion}

Figure 1a-c represents the SEM images of the typical fracture cross section at different magnifications and free surface microstructures exhibited by as-spun $\mathrm{Fe}_{68.45} \mathrm{Pd} \mathrm{d}_{28.21} \mathrm{Co}$.66 Ni1.66 ribbons (Figure 1a,b). Ribbon thickness fluctuated between 6 and $12 \mu \mathrm{m}$. Although the samples were obtained at high quenching rate, they were fully crystalline and showed a granular columnar type microstructure (Figure 1c). Furthermore, while the microstructure shows fracture surfaces of a cleavage type, EDX microanalysis demonstrates a nearly homogeneous chemical element distribution for as-spun ribbons (Figure 1d). Moreover, the composition analysis of the individual ribbons was found to be in good agreement with the nominal composition of the as-spun ribbons (68.01 at\% Fe-27.95 at\% Pd-1.59 at\% Co-1.65 at\% Ni).
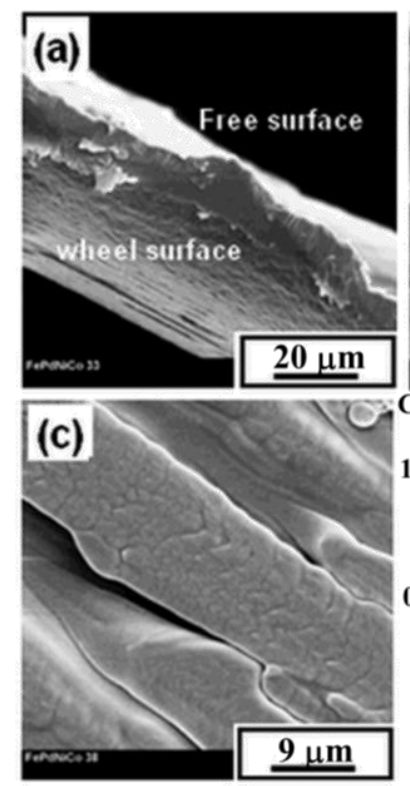
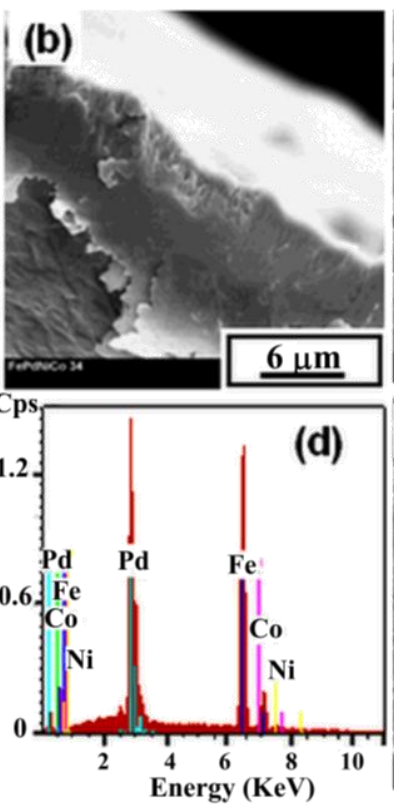
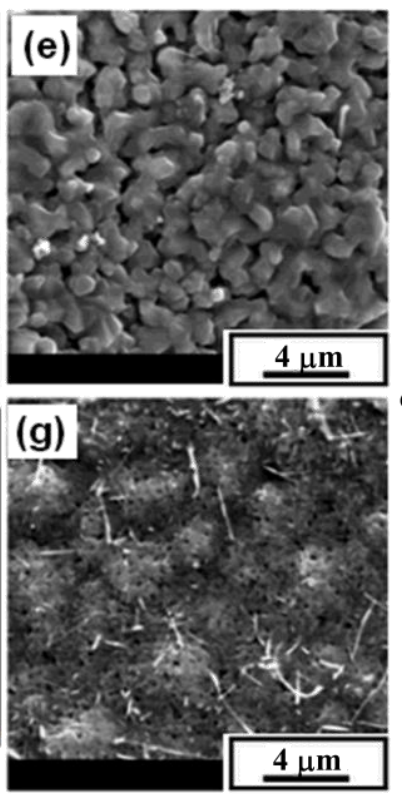

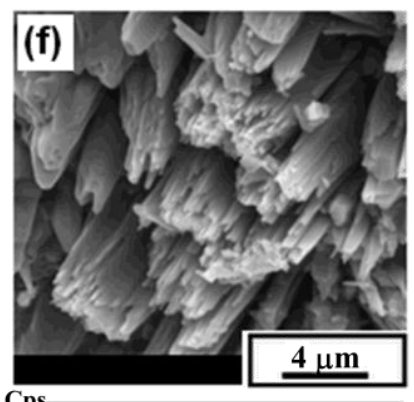

(h)

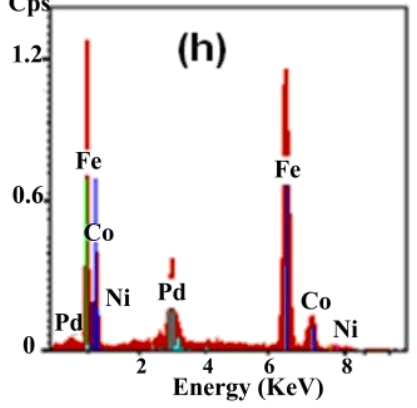

Figure 1. SEM micrographs of microstructure exhibited by as-spun and annealed $\mathrm{Fe}_{68.45} \mathrm{Pd}_{28.21} \mathrm{Co}_{1.66} \mathrm{Ni}_{1.66}$ ribbons at $600{ }^{\circ} \mathrm{C}$ for $1 \mathrm{~h}$ : (a) typical cross section; (b) higher magnification of cross section; (c) free surface for as-spun ribbons; (d) EDX corresponding to the as-spun ribbons; (e) free surface for annealed ribbons; (f) View of microwires growth; (g) wheel surface for annealed ribbons and (h) EDX corresponding to the annealed ribbons.

Figure 1e,g show the SEM micrographs of the free surface and the wheel surface sides of the annealed ribbons at $600{ }^{\circ} \mathrm{C}$ for $1 \mathrm{~h}$, respectively. At the free surface, the samples are provided with a microstructure consisting of granular, columnar grains growing through the ribbon thickness with their longer axis aligned perpendicular to the ribbon plane. Grain sizes fluctuated between 1 and $2 \mu \mathrm{m}$. Moreover, Figure 1f shows rather columnar structure as the microwires. From the wheel surface image, a cellular microstructure type can be noted. As can be seen in Figure 1g, the wetting of the melt by the copper wheel might not be fully complete since the surface of the ribbons was slightly wavy on the contact side. A certain microporosity of the annealed specimen is present. A nearly homogeneous distribution of the chemical elements was found (Figure 1h). 


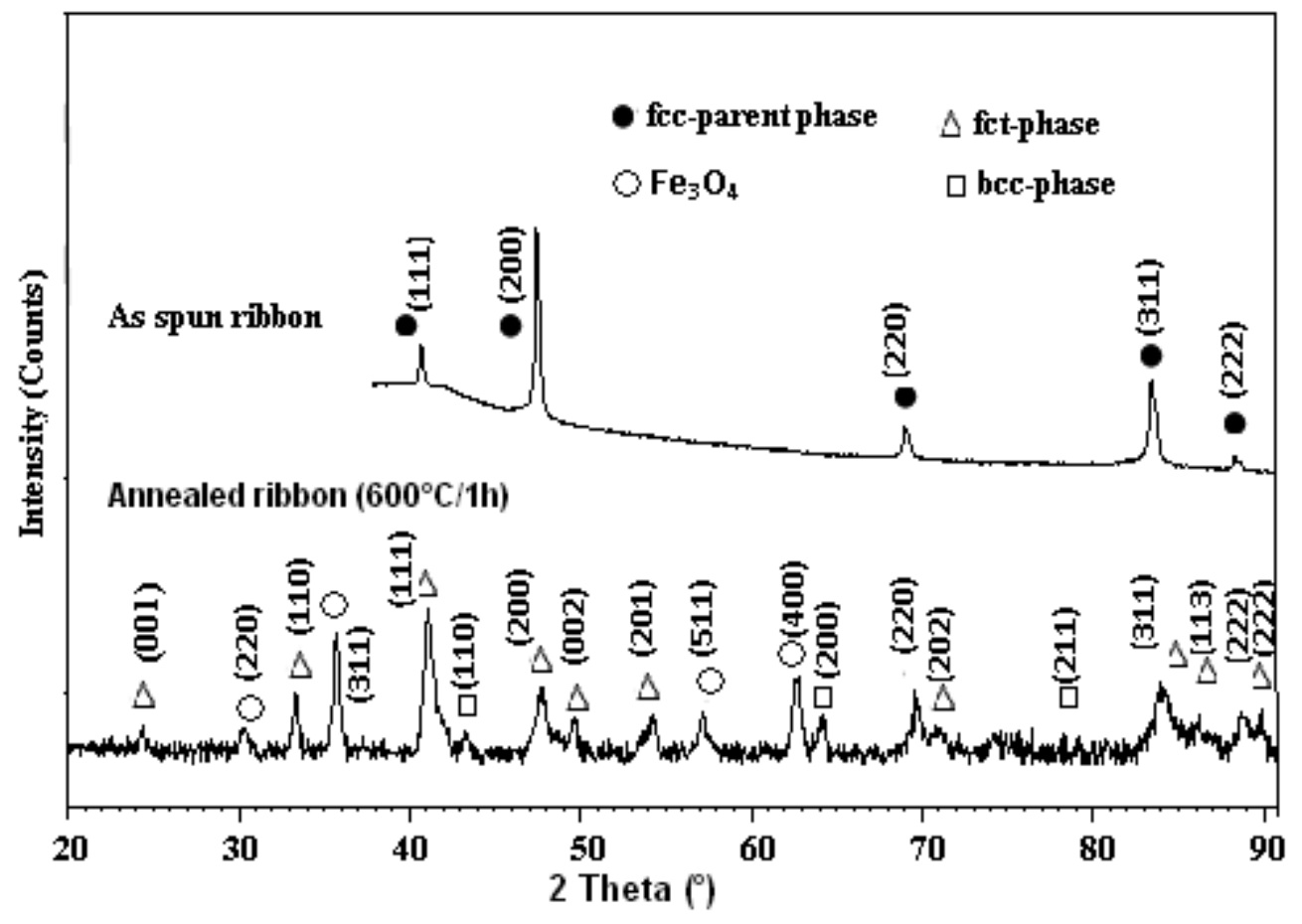

Figure 2. XRD patterns of as-spun and annealed $\mathrm{Fe}_{68.45} \mathrm{Pd}_{28.21} \mathrm{Co}{ }_{1.66} \mathrm{Ni}_{1.66}$ ribbons.

Figure 2 shows the XRD patterns of as-spun and annealed ribbons. All the Bragg peaks are sharp and indexed, building on a disordered fcc type structure of $(\gamma-\mathrm{Fe}, \mathrm{Pd})$ phase with space group Fm-3m and a lattice parameter $a=3.742(3) \AA$. This reveals that ribbons are fully-single phase with a cubic austenite parent phase. The direction [200] was found to be preferential for austenite phase, indicating that ribbons exhibit crystallographic texture in agreement with their grain-oriented columnar microstructure. The XRD pattern of the annealed ribbons shows that both the (200) and (220) reflection peaks of the disordered $\gamma$-(Fe,Pd) phase split into two peaks ((200), (002)) and ((220), (202)) reflections of the ordered FePd L10. This is as a result of ordering and transformation from cubic phase to tetragonal one. Furthermore, after annealing, both the (110) $\alpha$-Fe and (200) $\alpha$-Fe peaks appear anew as a result of decomposition. The Rietveld refinement analysis was done by means of the bcc-Fe, fct-FePd, and cubic $\mathrm{Fe}_{3} \mathrm{O}_{4}$ phases. The pattern of the as-spun sample is composed of reflections corresponding to disordered fcc $\gamma$-Fe(Pd) phase of the space group Fm-3m and the lattice parameter $a=0.3742(3) \mathrm{nm}$. This signifies that the as-spun ribbon sample is only single-phase - cubic austenite parent phase. The direction [200] is seen to be preferential for this austenite phase indicating that ribbon exhibits a crystallographic texture in agreement with the grain oriented columnar microstructure detected by SEM. The XRD pattern of the annealed ribbon shows that both (200) and (220) reflection peaks of the disordered $\gamma$-Fe(Pd) phase are split into two peaks; ((200), (002)) and into ((220), (202)) reflections of the ordered FePd L10 phase. This is a result of ordering and transformation from the cubic into tetragonal phase. Furthermore, the very small reflections (110) and (200) corresponding to the bcc $\alpha$-Fe phase appear as a result of a partial decomposition. In the Ref. [16], it has been reported that the tetragonal phase is usually identified by an occurrence of the superlattice reflections (001) and (110) of the fct-lattice representing unambiguously the $\mathrm{L} 10$ phase. These two superlattice peaks occur in Figure 2 at $2 \theta$ about $24^{\circ}$ and $33^{\circ}$, respectively. 
Based on an equation $[17,18]$ :

$$
\mathrm{S}^{2}=\frac{\mathrm{Is} \times\left[(\mathrm{Ff})^{2}(\mathrm{~L}) \mathrm{f} \times \exp (-2 \mathrm{M}) \mathrm{f} \times \mathrm{mf}\right]}{\text { If } \times\left[(\mathrm{Fs})^{2}(\mathrm{~L}) \mathrm{s} \times \exp (-2 \mathrm{M}) \mathrm{s} \times \mathrm{ms}\right]}
$$

and using the parameters $F_{f}=\left(f_{F e}+f_{P d}\right), F_{s}=\left(f_{P d}-f_{F e}\right), L=\left(1+\cos ^{2} 2 \theta\right) /\left(\sin ^{2} \theta \times \cos \theta\right)$, $\mathrm{M}=\mathrm{B}\left(\sin ^{2} \theta / \lambda^{2}\right), \mathrm{B}=0.00835 \mathrm{~nm}^{2}$ for superlattice (s) and fundamental (f) reflections, the LRO parameter close to 0.9 was determined for the annealed sample.

Figure 3 shows the one thermal cycle between room temperature and $600{ }^{\circ} \mathrm{C}$. An endothermic reaction at $358^{\circ} \mathrm{C}$ followed by an exothermic one at $390{ }^{\circ} \mathrm{C}$ can be observed on heating. When cooling to room temperature, no peak appeared. The endothermic reaction can be attributed to the $T_{\mathrm{c}}$ of $\mathrm{Ni}$. It can be detected by the change in heat and by the small amount of energy associated with this transition. The exothermic peak might be related to the annihilation of an excess of quenched-in vacancies. In general, rapidly solidified ribbons contain an excess of quenched-in vacancies. In fact, at high temperatures, the vacancies can be annihilated, as considered for Ni-Mn-Ga shape memory melt-spun ribbons [19] as well as for $\mathrm{FePd}_{3}$ alloy [20].

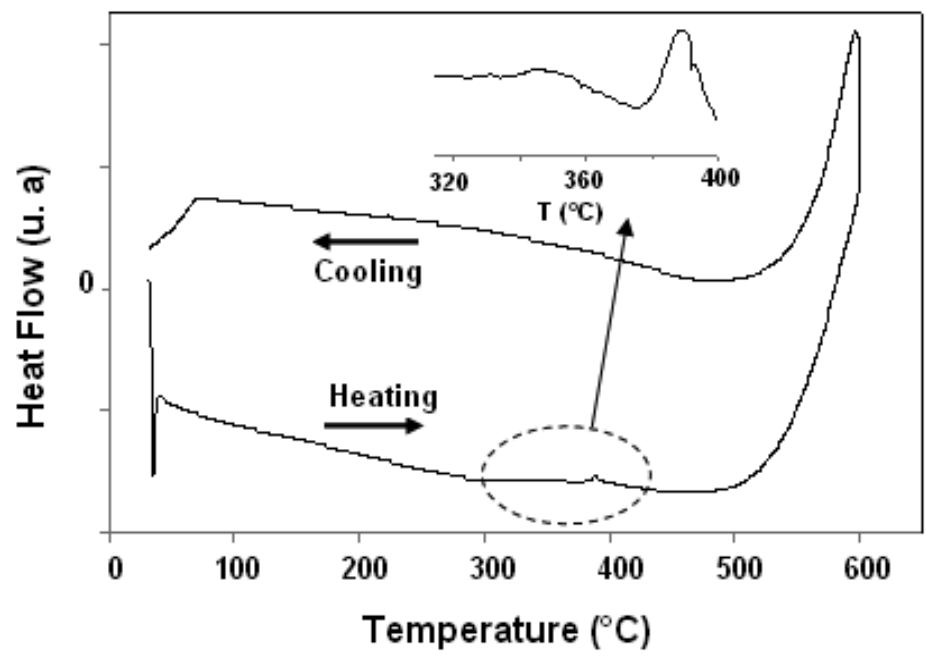

Figure 3. DSC scans for as-spun ribbons upon heating and cooling at a rate of $10 \mathrm{~K} / \mathrm{min}$.

The Mössbauer spectrum of the as-spun ribbons has been used to complement the XRD patterns in order to confirm the phase present in the sample and in order to try to assess the role of the $\mathrm{Ni}$ and Co additions. Figure 4 shows the experimental spectrum with the best fit (left) together with the hyperfine field distribution (right). The hyperfine Mössbauer parameters obtained after the fitting procedure were $\delta_{\text {avg }}=0.13(1) \mathrm{mm} / \mathrm{s}, B_{h f \text {,avg }}=34.10(9) \mathrm{T}, \sigma=5.2(1) \mathrm{T}, \varepsilon=-0.04$ (1) $\mathrm{mm} / \mathrm{s}, I_{2-3}=2.17$ (2), where the given values and the avg sub-index correspond to the average of the field distribution, $\sigma$ is the FWHM of the hyperfine field distribution, $\varepsilon$ is the quadrupole shift and $I_{2-1}$ is the ratio between the intensities of lines 1 and 2 of the sextet. The values in brackets correspond to the standard deviation of the data. From Figure 4, a broadening of the external lines of the spectrum is observed. Moreover, an increase in the intensity of the second and fifth peaks of the spectrum with respect the first and sixth peaks, respectively, has been also detected. The same effects have been previously found in other Fe-Pd alloys [21,22], although their origin is debated. In ref. [21] the broadening of the external lines is attributed to a superposition of a large number of sextets corresponding to the random arrangements of $\mathrm{Fe}$ and $\mathrm{Pd}$ 
neighbors in the first coordination sphere of Fe atoms. However, in ref. [22] the authors state that this explanation is not correct for high concentrations of $\mathrm{Fe}$ in $\mathrm{Pd}$ or in the case of ordered Fe-Pd solutions. In fact they fit the broad lines with a small number (up to ten) of discrete hyperfine fields assigned to the presence of a strong magnetic field induced by the $\mathrm{Pd}$ atoms. This conclusion is supported by the fact that in Fe-Pd nanoparticles the thermal fluctuations are important enough to decrease the splitting caused by the Pd field, thus reducing the broadening of the lines as it is observed in Mössbauer spectra of Fe-Pd nanoparticles. However, in the present study, XRD patterns are ascribed to a disordered fcc type structure, therefore it can be concluded that the broadening of the external lines is due to the disordered nature of the as-spun ribbons. The increase in intensity of the second and fifth peaks, revealed by the $I_{2-3}$ value, is an indication that the spins of the Fe atoms tend to be oriented in the ribbon plane.
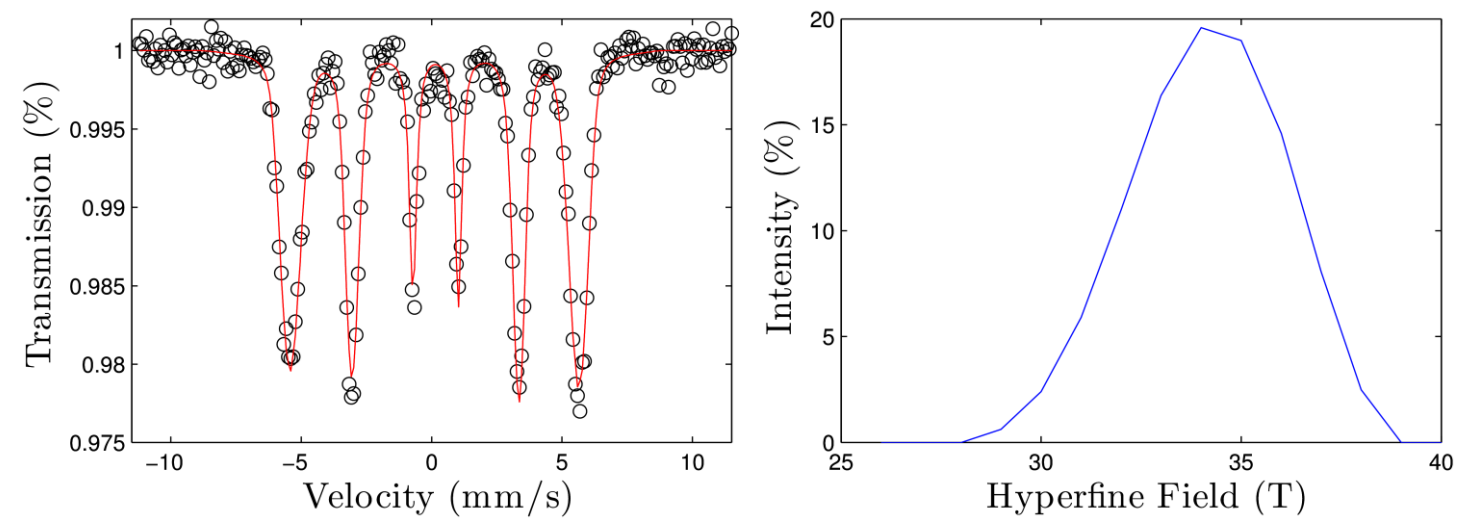

Figure 4. Collected Mössbauer spectra (left) with the experimental data (symbols) and the best fit (red line) and hyperfine magnetic fields distribution (right).

The obtained values of the hyperfine parameters allow us to identify the phases present in the as-spun ribbons. In fact, the resolution of Mössbauer spectroscopy is able to detect phases with a low content in $\mathrm{Fe}$ (with a minimum content around 5 at\% $\mathrm{Fe}$ ) that cannot be observed with XRD. Comparing the hyperfine parameters of this alloy with those recorded in the literature in alloys with similar composition [23], it can be concluded that only one phase is present in the specimen, a disordered Fe-Pd fcc phase.

The existence of a tetragonal fct phase should be discarded due to the low value of the quadrupole shift and the high value of the average hyperfine magnetic field. As a reference, in an fct Fe-Pd phase, $\varepsilon=0.38 \mathrm{~mm} / \mathrm{s}$ and $\mathrm{B}=28.1 \mathrm{~T}$ [24], values far from the measured ones. However, a fitting procedure to include an fct phase was implemented. The addition of a new sextet with fixed parameters (corresponding to the fct phase) to the hyperfine field distribution yield a worst overall fitting and with non-physical hyperfine parameters for the disordered fcc phase.

The effect of the minor addition of $\mathrm{Ni}$ and $\mathrm{Co}$ is more difficult to discern. There is not so much work on the Fe-Pd systems including $\mathrm{Ni}$ and $\mathrm{Co}$, although the effect of these atoms in Fe or Fe-Pd thin films has been studied [25-28]. The general trend is that these elements at low concentrations tend to increase the hyperfine magnetic field and the isomer shift. However, the samples studied in the present work are not thin films and, moreover, the structure of the ribbons is disordered, thus the only way to assess the influence of $\mathrm{Ni}$ and $\mathrm{Co}$ is to produce $\mathrm{Ni}$ - and $\mathrm{Co}$-free $\mathrm{Fe}-\mathrm{Pd}$ ribbons and compare the resulting hyperfine parameters. In this way, the possible small changes related to these minor additions could be detected. 
However, from the XRD analysis and from the Mössbauer hyperfine parameters some conclusions can be drawn. From the presented results it is clear that the actual phase is an fcc phase but according to [24] (where Fe-Pd alloys with different Pd content ranging from 2.2 to 100 at\% were analyzed) in bulk alloys with less than 35 at\% of Pd the present phase should be a bcc phase. That is, in bulk Fe-Pd alloys there is a transition from a bcc to a fcc phase increasing the Pd content. Therefore, in our case with 28.21 at\% of Pd we should obtain a bcc structure that has not been found either by XRD or Mössbauer spectroscopy. As the only difference in our samples is the presence of $\mathrm{Ni}$ and $\mathrm{Co}$, we conclude that the addition of these elements favors the formation of the fcc phase rather than the bcc phase expected by the Fe/Pd ratio. This conclusion should be confirmed and further work is being done, including the study of the annealed sample by Mössbauer spectroscopy that will be published elsewhere.

\section{Conclusions}

The prepared $\mathrm{Fe}_{68.45} \mathrm{Pd}_{28.21} \mathrm{Co}_{1.66} \mathrm{Ni}_{1.66}$ alloy ribbons by melt spinning were studied by means of SEM, XRD, DSC and Mössbauer techniques. The results have shown the formation of a single fcc type structure of $\gamma-(\mathrm{Fe}, \mathrm{Pd}, \mathrm{Co}, \mathrm{Ni})$ phase. The Mössbauer analysis has confirmed that $\mathrm{Ni}$ and $\mathrm{Co}$ addition favor the formation of the disordered fcc phase rather than the bcc phase expected by the Fe/Pd ratio. After annealing at $600{ }^{\circ} \mathrm{C}$ for $1 \mathrm{~h}$, an fct L10-ordered phase is usually identified. The identified endothermic and exothermic reactions may be attributed to the Curie temperature of nickel and to the annihilation of an excess of quenched-in vacancies, respectively.

\section{Acknowledgments}

Financial support from ACID project is acknowledged. P.B. was funded by MINECO grant FIS2014-54734-P and Generalitat de Catalunya grant 2014SGR00581. Authors would like to thank Leila Mahfoudhi from the English Language Unit at the Faculty of Sciences of Sfax (Tunisia) for accepting to proofread and polish the language of this paper.

\section{Author Contributions}

Joan Joseph Sunol and Mohamed Khitouni conceived, designed the experiments and wrote the SEM and XRD results; Hanen Rekik, Mahmoud Chemingui, Amal Cherif and Tarek Bachaga performed the experiments and analyzed the data; Pere Bruna performed the Mössbauer spectroscopy experiment and wrote their results section under the collaboration with Hanen Rekik. Tarek Bachaga, Mahmoud Chemingui and Amal Cherif performed the experiments and analyzed the data. All authors discussed the results and worked on preparing the manuscript.

\section{Conflicts of Interest}

The authors declare no conflict of interest.

\section{References}

1. Nakayama, T.; Kikuchi, M.; Fukamichi, K. Young's modulus and the Delta E effect of Fe-Pd Invar alloys. J. Phys. F 1980, 10, 715. 
2. Gehanno, V.; Marty, A.; Gilles, B.; Samson, Y. Magnetic domains in epitaxial ordered FePd (001) thin films with perpendicular magnetic anisotropy. Phys. Rev. B 1997, 55, 12552.

3. Cui, J.; Shield, T.W.; James, R.D. Phase transformation and magnetic anisotropy of an iron-Palladium ferromagnetic shape-memory alloy. J. Acta Mater. 2004, 52, 35-47.

4. Kato, H.; Liang, Y.; Taya, M. Stress-induced fcc/fct phase transformation in Fe-Pd alloy. Scr. Mater. 2002, 46, 471-475.

5. Matsui, M.; Shimizu, T.; Yamada, H.; Adachi, K. Magnetic properties and thermal expansion of Fe-Pd invar alloys. J. Magn. Magn. Mater. 1980, 15, 1201-1202.

6. Oshima, R.; Sugiyama, M. Martensite transformations in FePd alloys. J. Phys. IV 1982, 43, C4-383-C4-388.

7. Sugiyama, M.; Oshima, R.; Fujita, F.E. Martensite transformations in FePd alloy system. Trans. Jpn. Inst. Met. 1984, 25, 585.

8. Muto, S.; Oshima, R.; Fujita F.E. Nucleation and growth in martensitic transformations of ordered $\mathrm{Fe}_{3} \mathrm{Pt}$ alloys. Metall. Trans. A 1988, 19, 2931-2936.

9. Tanaka, K.; Oshima, R.; Fujita, F.E. Role of annealing twin in the formation of variant structure of bct martensite in Fe-Pd alloy. Mater. Trans. JIM 1991, 32, 325-330.

10. Sanchez-Alarcos, V.; Perez-Landazabal, J.I.; Recarte, V.; Gómez-Polo, C.; Rodríguez-Velamazán, J.A. Correlation between composition and phase transformation temperatures in $\mathrm{Ni}-\mathrm{Mn}-\mathrm{Ga}-\mathrm{Co}$ ferromagnetic shape memory alloys. Acta Mater. 2008, 56, 5370-5376.

11. Sanchez-Alarcos, V.; Recarte, V.; Perez-Landazabal, J.I.; González, M.A.; Rodríguez-Velamazán J.A. Effect of Mn addition on the structural and magnetic properties of Fe-Pd ferromagnetic shape memory alloys. J. Acta Mater. 2009, 57, 4224-4232.

12. Stern, R.A.; Wiiloughby, S.D.; Ramirez, A.; MacLaren, J.M.; Cui, J.; Pan, Q.; James, R.D. Electronic and structural properties of $\mathrm{Fe}_{3} \mathrm{Pd}-\mathrm{Pt}$ ferromagnetic shape memory alloys. J. Appl. Phys. 2002, 91, 7818-7820.

13. Lin, Y.C.; Lee, H.T.; Jen, S.U.; Chen, Y.T. Magnetic structure of an Fe-Pd-Rh alloy. J. Appl Phys. 2007, 101, doi:10.1063/1.2712174.

14. Jen, S.U.; Chen, Y.T.; Tsai, T.L.; Lin, Y.C. Magnetostrictive strains in polycrystalline FePdRh alloy. J. Appl Phys. 2008, 103, doi:10.1063/1.2830965.

15. Brand, R.A. NORMOS-98 Mössbauer Fitting Program Package; WissEl GmbH: Stanberg, Germany, 1998.

16. Gutfleisch, O.; Lyubina, J.; Müller, K.H.; Schultz, L. FePt hard magnets. Adv. Eng. Mater. 2005, 7, 208-212.

17. Khitouni, M.; Kolsi, A.W.; Njah, N. The effects of boron additions on the disordering and crystallite refinement of $\mathrm{Ni}_{3} \mathrm{Al}$ powders during mechanical milling. Ann. Chim. Sci. Matér. 2003, 28, 17-29.

18. Khitouni, M.; Njah, N.; Gilbon, D. The effect of boron on the reordering of $\mathrm{Ni}_{3} \mathrm{Al}$ powders produced by filing. Scr. Mater. 2004, 50, 77-81.

19. Seguí, C.; Pons, J.; Cesari, E.; Muntasell, J.; Font, J. Characterization of a hot-rolled Cu-Al-Ni-Ti shape memory alloy. Mater. Sci. Eng. A 1999, 273-275, 625-629.

20. Recarte, V.; Perez-Landazabal, J.I.; Gomez-Polo, C; Campo, J.; Garitaonandia, J.S. Influence of atomic rearrangements on the magnetic properties of a thermally treated disordered $\mathrm{Fe}_{21} \mathrm{Pd}_{79}$ alloy. J. Non-Cryst. Solids 2001, 287, 96-99. 
21. Ryzhenko, B.V.; Sidorenko, F.A.; Karpov, Y.G.; Gel'd, P.V. Effective fields at Fe57 nuclei and magnetic structure of palladium-iron alloys. Phys. JETP 1977, 73, 1032-1044.

22. Petrov, Yu.I.; Shafranovskii, E.A.; Krupyanskii, Yu.F.; Esin, S.V. Discrete Structure of the Hyperfine Field Distribution at Fe Nuclei in the Bulk FePd Alloy and Its Nanoparticles. Phys. Chem. 2004, 399, 269-274.

23. Claussen, I.; Brand, R.A.; Hahn, H.; Mayr, S.G. Relaxation scenarios in Fe-Pd and Fe-Pd-Cu ferromagnetic shape memory splats: Short range order and microstructure. Scr. Mater. 2012, 66, 163-166.

24. Gehanno, V.; Auric, P.; Marty, A.; Gilles, B. Structural and magnetic properties of epitaxial $\mathrm{Fe}_{0.5} \mathrm{Pd}_{0.5}$ thin films studied by Mössbauer spectroscopy. J. Magn. Magn. Mater. 1998, 188, 310-318.

25. Kamali-M, S.; Bergman, A.; Andersson, G.; Stanciu, V.; Häggström, L. Local Magnetic Effects of Interface Alloying in Fe/Co Superlattices. J. Phys. Condens. Matter 2006, 18, 5807-5824.

26. Kamali, S.; Häggström, L.; Sahlberg, M.; Wäppling, R. Magnetic and interface properties of $\mathrm{Fe}_{0.82} \mathrm{Ni}_{0.18} / \mathrm{Co}(001)$ superlattices. J. Phys. Condens. Matter 2011, 23, doi:10.1088/0953-8984/23/5/055301.

27. Kamali, S.; Blixt, A.M.; Häggström, L.; Wäppling, R.; Stanciu, V.; Nordblad, P. Magnetic properties of a $\mathrm{Fe}_{0.82} \mathrm{Ni}_{0.18} / \mathrm{V}(001)$ superlattice studied by Mössbauer spectroscopy. J. Magn. Magn. Mater. 2004, 272-276, 1263-1265.

28. Häggström, L.; Soroka, I.; Kamali, S. Thickness Dependent Crystallographic Transition in Fe/Ni Superlattices. J. Phys. Conf. Ser. 2010, 217, doi:10.1088/1742-6596/217/1/012112.

(C) 2015 by the authors; licensee MDPI, Basel, Switzerland. This article is an open access article distributed under the terms and conditions of the Creative Commons Attribution license (http://creativecommons.org/licenses/by/4.0/). 